\title{
SYNTHESIS AND BIOLOGICAL ACTIVITY OF C-3' ORTHO DIHYDROXYPHTHALIMIDO CEPHALOSPORINS
}

\author{
Marie-Geneviève Baudart and Laurent F. Hennequin* \\ ZENECA pharma, Centre de Recherches Chemin de Vrilly, \\ Z. I. la Pompelle, 51100 Reims, France
}

(Received for publication February 17, 1993)

\begin{abstract}
A series of $\mathrm{C}^{-3^{\prime}}$ ortho dihydroxyphthalimido cephalosporins $3 \sim 7$ has been prepared by reaction of $\mathrm{C}^{-3^{\prime}}$ aminomethyl cephalosporin $\mathbf{4 1}^{1}$ ) with the corresponding $N$-carboethoxyphthalimides 23 25, 37, 38. These new caphalosporins exhibit excellent in vitro Gram-negative activities, including Pseudomonas aeruginosa, excellent $\beta$-lactamases stability and pharmacokinetics equivalent or better than ceftriaxone.
\end{abstract}

A number of new cephalosporins possess potent and extended antibacterial spectra and have made an important contribution to the treatment of infection ${ }^{2)}$. However there is still a need for new semisynthetic cephalosporins with improved spectra, including Pseudomonas aeruginosa, increased $\beta$-lactamase stability (type I and plasmid mediated) and long half-lives.

Since the discovery by Eisai of a C-7 ureido cephalosporin bearing a catechol moiety, E- $0702^{3)}$, a new class of compounds, catechol containing cephalosporins, has emerged ${ }^{4 \sim 6)}$. The catechol moiety predisposes the cephalosporins to pass into the bacterial cells not only passively via porins, the standard route of entry for cephalosporins, but also via an iron-uptake pathway ${ }^{7,8)}$.

During a programme to design modified cephalosporins, our laboratories have focused their interest on attaching a catechol moiety at the C-3' position of the cephalosporin nucleus via an amidic linkage ${ }^{1,9)}$ such as in compound $\mathbf{1}$ (scheme 1).

We have found that such a combination leads to compounds having very good in vitro antibacterial activities, including $P$. aeruginosa, good type I $\beta$-lactamases stability and long half-lives ${ }^{1,9)}$.

Particularly outstanding $\beta$-lactamase stability has been observed in compounds such as $\mathbf{1}$ and might

Scheme 1 .<smiles></smiles>

$1 \quad \mathrm{R}_{1}=\mathrm{H}$

3

$2 \mathbf{R}_{1}=\mathrm{Et}$<smiles>[Y]N=C(C(=O)N[C@H]1C(=O)N2C(C(=O)O)=C(CC)CS[C@H]12)c1csc(N)n1</smiles> 
be explained partly by the hydrogen bond (Scheme 1) observed between the amidic NH and the carbonyl of the quinolone ring (1: NMR $\delta 10.4 \mathrm{ppm}$ in DMSO- $d_{6}$ compared to $8.3 \mathrm{ppm}$ for normal amidic compounds) which result in a planar C-3' substituent ${ }^{1)}$.

In order to understand the role played by the planar conformation of the $\mathrm{C}-3^{\prime}$ substituent and to further improve the type I $\beta$-lactamase stability, we decided to replace this labile hydrogen bond by a covalent one as in 3 (Scheme 1). The synthesis and biological properties of these new compounds are described in this paper.

\section{Chemistry}

The strategy used to prepare C- $3^{\prime}$ ortho dihydroxyphthalimido cephalosporins ${ }^{10)} 3 \sim 7$ involves $N$-carboethoxyphthalimides $23 \sim 25,37,38$ as intermediates. Such reagents are known to react smoothly with amines to give the corresponding $N$-phthalimido protected compound in good yield ${ }^{11}$. Thus we synthesized the functionalised catechol phthalimides $23 \sim 25,37,38$ and reacted them with the C-3' aminomethyl cephalosporin $\mathbf{4 1}{ }^{1}$.

3,4-Dimethoxytoluene was formylated using dichloromethylmethyl ether in the presence of tin chloride to give the aldehyde 10 (Scheme 2). The brominated isomer 11 was obtained from vanillin after monobromination and similar formylation. 10,11 were then oxidized with $\mathrm{KMnO}_{4}$ to give the diacids 12,13 which were transformed into the corresponding phthalimides 14,15 via the intermediate anhydrides. After deprotection of the catechol moiety using $\mathrm{BBr}_{3}, 17$ was chlorinated using $N$-chlorosuccinimide and paratoluenesulfonic acid. In order to avoid side reactions during the $N$-carboethoxylation step, the catechol moiety was reprotected with an acid labile group; the most convenient proved to be the diphenylmethyl moiety. Protected phthalimides $\mathbf{2 0} \sim 22$ were then reacted with $\mathrm{NaH}$ followed by ethyl chloroformate to give reagents $23 \sim 25$.

Condensation of $23 \sim 25$ with 41 in DMSO occurs smoothly at room temperature and the protected cephalosporins $26 \sim 28$ were isolated in very good yield. Final deprotection of the catechol moiety was achieved using trifluoroacetic acid in the presence of traces of water to give the free ortho dihydroxyphthalimido cephalosporins 3 5 (Scheme 2).

A similar strategy was used to generate the isomeric series, cephalosporins 6 and 7 (Scheme 3).

In addition, compound $\mathbf{8}$ (Table 1) used here as a comparator was obtained following a similar sequence starting from commercially available $N$-carboethoxyphthalimide.

\section{Biological Results and Discussion}

MIC values $(\mu \mathrm{g} / \mathrm{ml})$ of the C- $3^{\prime}$ ortho dihydroxyphthalimido cephalosporins $3 \sim 7$ against a selection of Gram-positive and Gram-negative bacteria are shown in Table 1. Compounds $3 \sim 7$ have been compared with cephalosporin 1 and 2 (Scheme 1) and with classical standards.

A first look at Table 1 shows that activities of phthalimides $3 \sim 7$ are superior to simple monocyclic catechols such as 9 (Table 1) having a phenolic $\mathrm{p} K a \approx 9$, against $E$. cloacae, $P$. stuartii, C. freudii, $S$. marcescens and P. morganii. Against $P$. aeruginosa $3 \sim 7$ are equivalent to 9 .

The level of activity against Gram-negative organisms obtained with the parent deshydroxyphthalimido cephalosporin 8, compared with phthalimides $3 \sim 5$ underlines clearly the importance of the ortho-dihydroxy function.

Comparison of biological activities against P. aeruginosa $799 / 61$ and Escherichia coli DC2, the permeability mutants lacking the outer membrane of 799WT and DC0, respectively, shows that $3 \sim 5$ 
Scheme 2. Synthesis of cephalosporines 3, 4, and 5 .

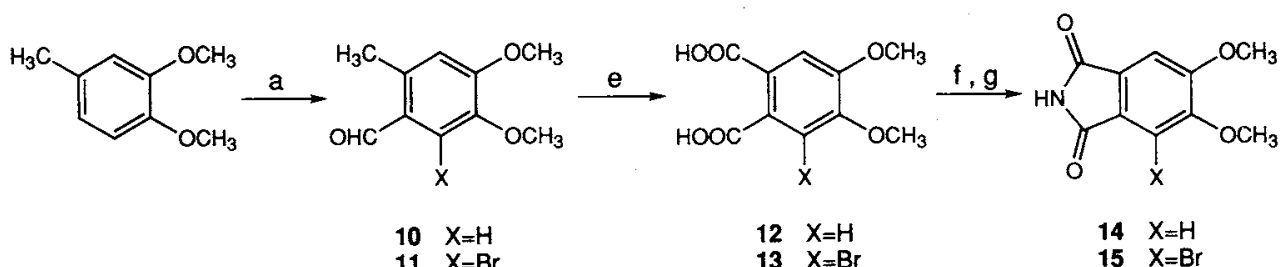<smiles>COc1cc(C=O)ccc1O</smiles>

16

$13 \quad X=B r$

$\begin{array}{ll}14 & X=H \\ & X=B r\end{array}$<smiles>CC1CC1C</smiles><smiles>[3H]C=O</smiles>
h<smiles>CC(C)CC(C)C</smiles>

19<smiles>[X]c1c2c(c([X])c3c1C(=O)NC3=O)OC(c1ccccc1)(c1ccccc1)O2</smiles><smiles>[X]c1c2c(c([X])c3c1C(=O)N(C(=O)CC)C3=O)OC(c1ccccc1)(c1ccccc1)O2</smiles><smiles></smiles>

41

$$
\begin{array}{lll} 
& X & Y \\
23 & H & H \\
24 & B r & H \\
25 & C l & C l
\end{array}
$$$$
\begin{array}{lll} 
& \mathrm{X} & \mathrm{Y} \\
26 & \mathrm{H} & \mathrm{H} \\
27 & \mathrm{Br} & \mathrm{H} \\
28 & \mathrm{Cl} & \mathrm{Cl}
\end{array}
$$<smiles>CC(=O)ON=C(C(C)=O)c1csc(N)n1</smiles><smiles>[R2]N[C@H]1C(=O)N2C(C(=O)O)=C(CN3C(=O)c4c([X])c(O)c(O)c([Y])c4C3=O)CS[C@H]12</smiles>

a) $\mathrm{Cl}_{2} \mathrm{CHOCH}_{3}, \mathrm{SnCl}_{4}$, b) $\mathrm{Br}_{2}, \mathrm{CH}_{3} \mathrm{COOH}$, c) $\left(\mathrm{CH}_{3}\right)_{2} \mathrm{SO}_{4}, \mathrm{~K}_{2} \mathrm{CO}_{3}$, d) 1) $\mathrm{NH}_{2} \mathrm{NH}_{2}$, 2) $\mathrm{KOH}$, e) $\mathrm{KMnO}_{4}, \mathrm{~K}_{2} \mathrm{CO}_{3}$, f) $\mathrm{AC}_{2} \mathrm{O}, \mathrm{g}$ ) $\mathrm{NH}_{4} \mathrm{OH}$, h) $\mathrm{BBr}_{3}$, i) $N$-chlorosuccinimide, paratoluenesulfonic acid, j) $\left.\mathrm{Ph}_{2} \mathrm{CCl}_{2} 160^{\circ} \mathrm{C}, \mathrm{k}\right)$ 1) $\mathrm{NaH}, \mathrm{DMF}$, 2) $\mathrm{ClCO}_{2} \mathrm{Et}$, l) $\mathrm{Et}_{3} \mathrm{~N}$, DMSO, m) TFA, $\mathrm{H}_{2} \mathrm{O}$. 
Scheme 3. Synthesis of cephalosporines 6 and 7.

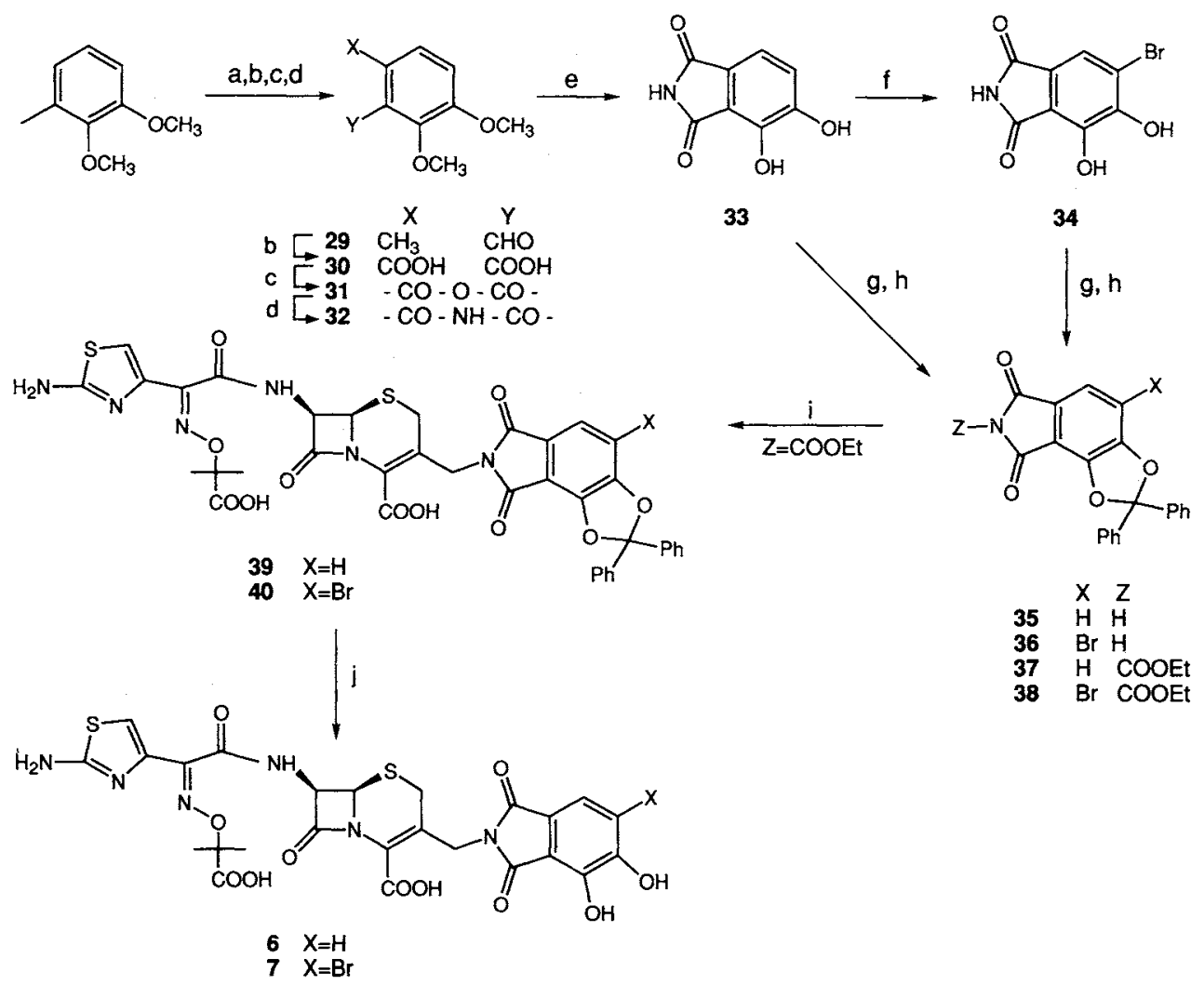

a) $\mathrm{Cl}_{2} \mathrm{CHOCH}_{3}, \mathrm{SnCl}_{4}$, b) $\mathrm{KMnO}_{4}, \mathrm{~K}_{2} \mathrm{CO}_{3}$, c) $\mathrm{Ac}_{2} \mathrm{O}$, d) $\mathrm{NH}_{4} \mathrm{OH}$, e) $\mathrm{BBr}_{3}, \mathrm{CH}_{2} \mathrm{Cl}_{2}$, f) $\mathrm{Br}_{2}$, $\mathrm{CH}_{3} \mathrm{COOH}$, g) $\mathrm{Ph}_{2} \mathrm{CCl}_{2}$, h) 1) $\left.\mathrm{NaH}, \mathrm{THF}, 2\right) \mathrm{ClCO}_{2} \mathrm{Et}$, i) 41, $\mathrm{Et}_{3} \mathrm{~N}, \mathrm{DMSO}$, j) TFA, $\mathrm{H}_{2} \mathrm{O}$.

(MIC's: $0.001 \sim 0.008 \mu \mathrm{g} / \mathrm{ml}$ ) and the parent 8 (MIC: $0.008 \mu \mathrm{g} / \mathrm{ml}$ ) have similar intrinsic activity. However comparison of activities against $P$. aeruginosa $799 \mathrm{WT}$ and $E$. coli DC0 and their permeability mutants $799 / 61$ and $D C 2$, respectively shows that molecules $3 \sim 5$ bearing a catechol residue at $C-3^{\prime}$ penetrate well into bacteria (ratio $799 \mathrm{WT} / 799 / 61: \mathbf{3} \sim \mathbf{5}=1$ to 2 ; Ceftazidime $=30$ ) while $\mathbf{8}$ is much less efficient (ratio $799 \mathrm{WT} / 799 / 61=1,000$ ). The result of passive diffusion is well represented by the activity of 8 against P. aeruginosa 799WT $(\mathrm{MIC}=8 \mu \mathrm{g} / \mathrm{ml})$.

This clearly indicates that the catechol moiety facilitates the penetration through the outer membrane of bacteria.

The mechanism of penetration has been shown to be ton $\mathrm{B}$ dependent ${ }^{8)}$, the known functionality of the ton B gene product concerning the transport of iron-chelated siderophores in $E$. coli.

Against Gram-positive organisms $3 \sim 5$ are less active than cefpirome and cefepime. Against Streptococcus pneumoniae and Streptococcus pyogenes $\mathbf{4}$ and $\mathbf{5}$ are just equivalent to ceftazidime, $\mathbf{4}$ being the best compound.

Against inducible and derepressed type I $\beta$-lactamase-producers (see Table 1 , footnotes b, e) P. aeruginosa, Enterobacter cloacae, Providencia stuartii, Citrobacter freundii, Serratia marcescens, Proteus morganii and Klebsiella oxytoca, C-3' ortho dihydroxyphthalimido cephalosporins $3 \sim 7$ are superior to 
Table 1. Antibacterial properties of C-3' ortho dihydroxyphthalimido cephalosporins comparison with standards (MIC's $\mu \mathrm{g} / \mathrm{ml})^{2}$.
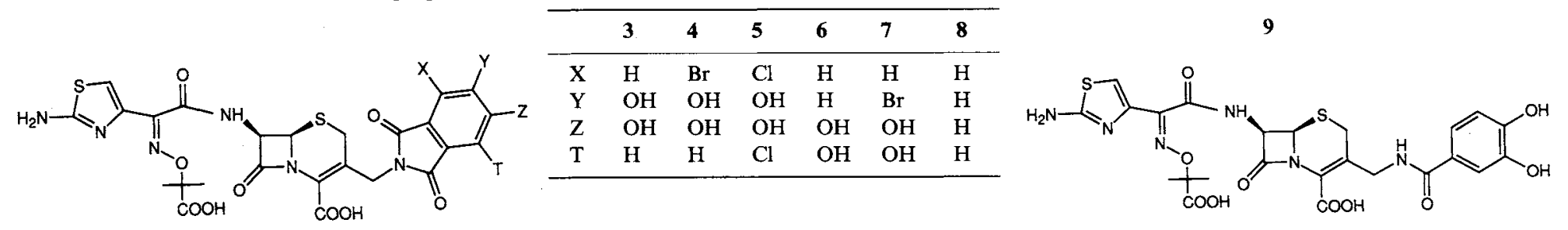

\begin{tabular}{|c|c|c|c|c|c|c|c|c|c|c|c|c|}
\hline \multirow{2}{*}{ Organisms } & \multicolumn{12}{|c|}{ Compounds } \\
\hline & 3 & 4 & 5 & 6 & 7 & 8 & 1 & 2 & Ceftazidime & Cefpirome & Cefepime & 9 \\
\hline \multicolumn{13}{|c|}{ Pseudomonas aeruginosa } \\
\hline $18 \mathrm{~S}^{\mathrm{e}}$ & $\leq 0.008$ & 0.004 & 0.004 & $\leq 0.008$ & $\leq 0.008$ & 16 & $\leq 0.008$ & 0.015 & 2 & 8 & 4 & 0.008 \\
\hline $18 \mathrm{SSAI}^{\mathrm{f}}$ & $\leq 0.008$ & 0.004 & 0.008 & $\leq 0.008$ & $\leq 0.008$ & 16 & $\leq 0.008$ & 0.015 & 1 & 2 & 1 & 0.008 \\
\hline $18 \mathrm{SSH}^{\mathrm{b}}$ & $\leq 0: 008$ & 0.004 & 0.004 & $\leq 0.008$ & $\leq 0.008$ & 8 & $\leq 0.008$ & 0.125 & 32 & 32 & 16 & 0.06 \\
\hline 50 & $\leq 0.008$ & 0.008 & 0.008 & 0.008 & $\leq 0.008$ & 2 & 0.015 & 0.015 & 2 & 1 & 0.5 & 0.008 \\
\hline 50DR & $\leq 0.008$ & 0.015 & 0.015 & 0.008 & $\leq 0.008$ & 8 & 0.03 & 0.125 & 32 & 16 & 8 & 0.125 \\
\hline $799 \mathrm{WT}^{\mathrm{c}}$ & $\leq 0.008$ & 0.001 & 0.002 & $\leq 0.008$ & $\leq 0.008$ & 8 & $\leq 0.008$ & 0.015 & 0.25 & 0.125 & 0.06 & 0.008 \\
\hline $799 / 61^{\mathrm{d}}$ & $\leq 0.008$ & 0.002 & 0.004 & $\leq 0.008$ & $\leq 0.008$ & $\leq 0.008$ & $\leq 0.008$ & 0.015 & $\leq 0.008$ & $\leq 0.008$ & $\leq 0.008$ & 0.008 \\
\hline PU21 & $\leq 0.008$ & 0.008 & 0.015 & $\leq 0.008$ & $\leq 0.008$ & 16 & 0.03 & 0.03 & 1 & 1 & 1 & - \\
\hline \multicolumn{13}{|c|}{ Enterobacter cloacae } \\
\hline $\mathrm{P} 99^{-\mathrm{e}}$ & $\leq 0.008$ & 0.06 & 0.03 & 0.03 & 0.015 & 2 & 0.06 & 0.125 & 0.125 & 0.06 & 0.03 & 0.5 \\
\hline $\mathrm{P} 99^{+\mathrm{b}}$ & 0.03 & 0.125 & 0.06 & 0.06 & 0.06 & 16 & 0.06 & 1 & 32 & 0.5 & 0.25 & 16 \\
\hline $\mathrm{I}^{+} 401029^{\mathrm{e}}$ & 0.015 & 0.015 & 0.015 & $\leq 0.008$ & 0.015 & 1 & 0.06 & 0.06 & 0.125 & 0.03 & 0.03 & 0.25 \\
\hline DR $401108^{b}$ & 0.5 & 0.5 & 0.25 & 0.25 & 1 & 8 & 1 & 2 & 32 & 0.25 & 0.125 & $>128$ \\
\hline
\end{tabular}




\begin{tabular}{|c|c|c|c|c|c|c|c|c|c|c|c|c|}
\hline \multicolumn{13}{|c|}{ Providencia stuartii } \\
\hline $\mathrm{I}^{+} 442019^{\mathrm{e}}$ & $\leq 0.008$ & 0.004 & 0.004 & 0.015 & 0.06 & 2 & 0.25 & 1 & 0.25 & 0.125 & 0.06 & 0.125 \\
\hline DR $442049^{b}$ & 0.125 & 0.015 & 0.015 & 0.25 & 0.5 & 4 & 8 & 16 & 4 & 0.5 & 0.125 & 1 \\
\hline \multicolumn{13}{|c|}{ Citrobacter freundii } \\
\hline $\mathrm{I}^{+} 382010^{\mathrm{e}}$ & $\leq 0.008$ & 0.001 & 0.001 & $\leq 0.008$ & $\leq 0.008$ & 1 & $\leq 0.008$ & $\leq 0.008$ & 0.125 & 0.015 & 0.015 & 0.03 \\
\hline DR $382031^{b}$ & 0.06 & 0.125 & 0.06 & 0.125 & 0.125 & 32 & 0.125 & 1 & 128 & 1 & 0.5 & 32 \\
\hline \multicolumn{13}{|c|}{ Serratia mercescens } \\
\hline $\mathrm{I}^{+} 421003^{\mathrm{e}}$ & $\leq 0.008$ & 0.004 & 0.004 & $\leq 0.008$ & $\leq 0.008$ & 4 & 0.015 & 0.03 & 0.25 & 0.06 & 0.06 & 0.06 \\
\hline DR $421078^{b}$ & $\leq 0.008$ & 0.004 & 0.004 & $\leq 0.008$ & $\leq 0.008$ & 4 & 0.015 & 0.125 & 0.5 & 0.06 & 0.125 & 0.06 \\
\hline \multicolumn{13}{|l|}{ Proteus morganii } \\
\hline $\mathrm{I}^{+} 433001^{\mathrm{e}}$ & $\leq 0.008$ & 0.004 & 0.004 & $\leq 0.008$ & $\leq 0.008$ & 1 & 0.125 & 0.5 & 0.125 & 0.03 & 0.03 & 0.125 \\
\hline DR $433062^{\circ}$ & 0.03 & 0.03 & 0.015 & 0.06 & 0.03 & 4 & 1 & 8 & 8 & 0.125 & 0.03 & 8 \\
\hline \multicolumn{13}{|c|}{ Klebsiella oxytoca } \\
\hline $\mathrm{K} 1^{+} 395056^{\mathrm{e}}$ & $\leq 0.008$ & 0.002 & 0.004 & $\leq 0.008$ & $\leq 0.008$ & - & $\leq 0.008$ & - & 0.5 & 1 & $i$ & - \\
\hline $\mathrm{K} 1^{-} 395055$ & $\leq 0.008$ & 0.001 & 0.004 & $\leq 0.008$ & $\leq 0.008$ & - & $\leq 0.008$ & - & 0.06 & - & 0.008 & 0.015 \\
\hline \multicolumn{13}{|l|}{ Escherichia coli } \\
\hline $\mathrm{DCO}^{\mathrm{c}}$ & $\leq 0.008$ & 0.001 & 0.002 & $\leq 0.008$ & $\leq 0.008$ & 1 & $\leq 0.008$ & $\leq 0.008$ & 0.125 & 0.015 & 0.015 & 0.008 \\
\hline $\mathrm{DC} 2^{\mathrm{d}}$ & $\leq 0.008$ & 0.001 & 0.001 & $\leq 0.008$ & $\leq 0.008$ & 0.06 & $\leq 0.008$ & $\leq 0.008$ & 0.06 & 0.015 & 0.015 & 0.008 \\
\hline \multicolumn{13}{|c|}{ Staphylococcus aureus } \\
\hline Oxford $^{\mathrm{f}}$ & 16 & 16 & 8 & 16 & 8 & 8 & 16 & 32 & 4 & 0.125 & 0.25 & 8 \\
\hline $147 \mathrm{~N}^{\mathrm{f}}$ & 16 & 16 & 16 & 16 & 16 & 8 & 16 & 64 & 4 & 0.25 & 0.5 & 16 \\
\hline \multicolumn{13}{|c|}{ Streptococcus pneumoniae } \\
\hline 671001 & - & 0.125 & 0.25 & - & 0.5 & 0.25 & 0.25 & 0.25 & 0.125 & 0.015 & 0.015 & 0.125 \\
\hline \multicolumn{13}{|c|}{ Streptococcus pyogenes } \\
\hline 681018 & - & 0.25 & 0.5 & 0.5 & 1 & 0.06 & 0.25 & 1 & 0.125 & $\leq 0.008$ & $\leq 0.008$ & - \\
\hline
\end{tabular}

${ }^{a}$ IST growth medium, inoculum $10^{4}$ cfu per spot, $37^{\circ} \mathrm{C} ;{ }^{b}$ constitutive derepressed type I $\beta$-lactamase-producer; ${ }^{\mathrm{c}}$ parent organism; ${ }^{\mathrm{d}}$ permeability mutant; ${ }^{\mathrm{e}}$ inducible type I $\beta$-lactamase producer; ${ }^{\mathrm{f}}$ non inducible mutant; ${ }^{\mathrm{g}}$ penicillin-sensitive $S$. aureus. 
Table 2. Pharmacokinetics measured in marmosets following intravenous administration of a $3 \mathrm{mg} / \mathrm{kg}$ dose.

\begin{tabular}{ccccc}
\hline Compound & $\begin{array}{c}\text { AUC* } \\
\text { (mg/hour per liter) }\end{array}$ & $\begin{array}{c}\text { Half-life* } \\
\text { (hours) }\end{array}$ & $\begin{array}{c}\text { Conc.* (at } 3 \text { hours) } \\
\text { (mg/liter) }\end{array}$ & $\begin{array}{c}\text { Measured } \\
\text { pKa }\end{array}$ \\
\hline $\mathbf{3}$ & 18.2 & 0.66 & 0.9 & 7.1 \\
$\mathbf{4}$ & $113 \sim 152$ & $1.8 \sim 3.3$ & $14.2 \sim 18.0$ & 5.9 \\
$\mathbf{5}$ & 62.6 & 1.5 & 8.1 & 5.3 \\
$\mathbf{6}$ & 36.4 & 1.3 & 4.4 & 6.3 \\
7 & 80.9 & 2.0 & 8.0 & 5.3 \\
Ceftriaxone & 75.7 & 1.5 & 8.8 & - \\
\hline
\end{tabular}

* Measured by bioassay.

ceftazidime. $3 \sim 7$ also proved to be 2 to 100 times more active against constitutive derepressed and inducible type I $\beta$-lactamases-producing strains than cefepime and cefpirome (Table 1).

Comparison of mic's against $\beta$-lactamase-derepressed producers (Table 1 footnote $b$ ) and the corresponding $\beta$-lactamase-inducible producers (Table 1 footnote e) indicates that $3 \sim 7$ are more stable to $\beta$-lactamases than the monocyclic catechol and than ceftazidime $\left(E\right.$. cloacae $\mathrm{P}^{+} / 9^{+} / \mathrm{P}^{-}: 3 \sim 7$ : ratio $=2 \sim 4,9:$ ratio $=32$, ceftazidime: ratio $=256 ;$ C. freundii DR382031/1 $\mathrm{I}^{+} 382010: 3 \sim 7$ : ratio $=7.5 \sim 125$, 9: ratio $=1,067$, ceftazidime: ratio $=1,024$ ). Similar comparisons indicates (Table 1) that $\mathrm{C}-3^{\prime}$ ortho dihydroxyphthalimido cephalosporins $3 \sim 7$ are marginally more stable to $\beta$-lactamases than cefepime and cefpirome, the accepted type I "stable cephalosporins", against $E$. cloacae (comparison $\mathrm{P} 99^{+} / \mathrm{P} 99^{-}$) and C. freundii ( $\mathrm{I}^{+}$382010/DR382031) but are very similar against $E$. cloacae (comparison I ${ }^{+}$401029/DR401108), $P$. stuartii, S. marcescens and $P$. morganii (see Table 1 ).

Overall the activity and stability against constitutive and inducible derepressed type I $\beta$-lactamaseproducing strains has been improved. These results showed clearly that the stability observed in compounds possessing an $\mathrm{H}$-bonding between the $\mathrm{NH}$ of the $\mathrm{C}-3^{\prime}$ amidic linkage and the carbonyl group of the quinolone moiety (Scheme 1) (comparison of 1 and 2) has been reinforced in phthalimido catechol cephalosporin such as 3 . Furthermore the bulk of C-3' phthalimido substituents as well as the acidity of the $\mathrm{OH}$ of the ortho-dihydroxy moiety reinforce the observation that hindrance at $\mathrm{C}-3^{\prime}$ and acidity of the catechol ${ }^{1,9)}$ improves the $\beta$-lactamase stability.

The pharmacokinetics of 5 and 7 measured in the marmoset (Table 2) were equivalent to those of ceftriaxone, an injectable cephalosporin suitable for once-daily dosing. 4 is clearly superior as measured by either half-life or the elevation of serum level which results in higher AUC's. As previously observed") these pharmacokinetic parameters seem related to the $\mathrm{pKa}$ of the catechol moiety: molecules highly ionised at physiological pH have the longest pharmacokinetics (Table 2 comparison of 3 with 4 and 5 and comparison of 6 with 7). Nevertheless comparison of 4 and 5 (Table 2) indicates that additionnal factors can modulate the pharmacokinetics of such compounds. Amongst them we could probably suspect the serum protein binding and the ability of catechol-cephalosporins to be metabolized by the enzyme catechol- $O$-methyltransferase $(\mathrm{COMT})^{12}$.

Urinary recoveries (measured in marmosets, single iv dose of $3 \mathrm{mg} / \mathrm{kg}$ ) of these compounds are equivalent to ceftriaxone; values of $\approx 25 \%$ suggest a significant degree of biliary excretion. All three compounds are highly found to Human serum protein (measured at $50 \mathrm{mg} /$ liter), ranking from $94 \%$ for 3 (equivalent to ceftriaxone) to $99.6 \%$ for $\mathbf{4}$ and $98 \%$ for $\mathbf{5}$. 


\section{Experimental}

IR spectra were recorded as $\mathrm{KBr}$ pellets on a Perkin-Elmer 781 spectrophotometer. ${ }^{1} \mathrm{H}$ NMR were recorded on a JEOL FX90Q or a Brucker $300 \mathrm{AC}$ spectrometer. FAB mass spectra were obtained on a VG 7250 SA mass spectrometer. Analytical HPLC chromatography was carried out on Shimadzu LC6A apparatus using nucleosil $\mathrm{C} 185 \mu \mathrm{m}$ columns, eluent $\mathrm{MeOH}-\mathrm{H}_{2} \mathrm{O}$ with 1:100 AcOH. Preparative medium pressure chromatography was carried out using Mitsubishi HP20SS resin, eluent $\mathrm{MeOH}-\mathrm{H}_{2} \mathrm{O}$ with 1:100 $\mathrm{AcOH}$. C-3'-Aminomethyl cephalosporin 41 was described in the literature ${ }^{1,13)}$.

\section{4,5-Dimethoxy-2-methylbenzaldehyde (10)}

To a solution of 3,4-dimethoxytoluene $(15 \mathrm{~g}, 98.6 \mathrm{mmol})$ and dichloromethylmethyl ether $(34.5 \mathrm{~g})$ in dichloroethane $(200 \mathrm{ml})$, at $0^{\circ} \mathrm{C}$, was added $\mathrm{SnCl}_{4}(100 \mathrm{ml})$ and, subsequently, further dichloroethane $(200 \mathrm{ml})$. The resultant suspension was stirred at $0^{\circ} \mathrm{C}$ for 20 minutes and then stirred overnight at ambient temperature before being poured into $3 \mathrm{~N} \mathrm{HCl}(500 \mathrm{ml})$ at $0^{\circ} \mathrm{C}$. Extraction into dichloromethane, drying of the organic phase and evaporation gave 4,5-dimethoxy-2-methylbenzaldehyde ${ }^{14)}(15.2 \mathrm{~g}) ;{ }^{1} \mathrm{H}$ NMR $\left(\mathrm{CDCl}_{3}\right) \delta 2.6(\mathrm{~s}, 3 \mathrm{H}), 3.90(\mathrm{~s}, 3 \mathrm{H}), 3.94(\mathrm{~s}, 3 \mathrm{H}), 6.68(\mathrm{~s}, 1 \mathrm{H}), 7.3(\mathrm{~s}, 1 \mathrm{H}), 10.2(\mathrm{~s}, 1 \mathrm{H}) ; \mathrm{CI}-\mathrm{MS} m / z$ $181\left(\mathrm{M}+\mathrm{H}^{+}, \mathrm{C}_{10} \mathrm{H}_{13} \mathrm{O}_{3}\right) ; \mathrm{mp} 76 \sim 78^{\circ} \mathrm{C}$.

Anal Calcd for $\mathrm{C}_{10} \mathrm{H}_{12} \mathrm{O}_{3}$ : C $66.65, \mathrm{H} 6.71$.

Found $\quad \mathrm{C} 66.62, \mathrm{H} 6.98$.

11, 29 ${ }^{15)}$ were prepared in a similar way:

11: yield 98\%; ${ }^{1} \mathrm{H}$ NMR (DMSO- $\left.d_{6}\right) \delta 2.52(\mathrm{~s}, 3 \mathrm{H}), 3.77(\mathrm{~s}, 3 \mathrm{H}), 3.9(\mathrm{~s}, 3 \mathrm{H}), 7.0(\mathrm{~s}, 1 \mathrm{H}), 10.3(\mathrm{~s}$, $1 \mathrm{H})$; IR $v_{\max } \mathrm{cm}^{-1} 1680,1595$; CI-MS $m / z 259,261\left(\mathrm{M}+\mathrm{H}^{+}, \mathrm{C}_{10} \mathrm{H}_{12} \mathrm{O}_{3} \mathrm{Br}\right) ; \mathrm{mp} 114 \sim 115^{\circ} \mathrm{C}$.

Anal Calcd for $\mathrm{C}_{10} \mathrm{H}_{11} \mathrm{O}_{3} \mathrm{Br}$ : $\mathrm{C} 46.33, \mathrm{H} 4.25$.

Found

C $46.57, \mathrm{H} 4.46$.

29: yield 70\%; ${ }^{1} \mathrm{H}$ NMR (DMSO- $\left.d_{6}, \mathrm{CF}_{3} \mathrm{COOD}\right) \delta 2.45(\mathrm{~s}, 3 \mathrm{H}), 3.7(\mathrm{~s}, 3 \mathrm{H}), 3.85(\mathrm{~s}, 3 \mathrm{H}), 7.0(\mathrm{~d}, 1 \mathrm{H})$, $7.55(\mathrm{~d}, 1 \mathrm{H}), 9.99(\mathrm{~s}, 1 \mathrm{H})$; IR $v_{\max } \mathrm{cm}^{-1} 1690,1600$. A sample recrystallized twice from petroleum ether gave a melting point of $52 \sim 54^{\circ} \mathrm{C}\left(\right.$ (lit. $^{15)} \mathrm{mp} 53.5 \sim 54.5^{\circ} \mathrm{C}$ ).

\section{2-Carboxy-4,5-dimethoxybenzoic Acid (12)}

To aldehyde $10(5 \mathrm{~g}, 44.4 \mathrm{mmol})$ and potassium carbonate $(5 \mathrm{~g})$ in water $(21 \mathrm{ml})$ at $80^{\circ} \mathrm{C}$ was added, in one portion, a solution of potassium permanganate $(19 \mathrm{~g})$ in water $(170 \mathrm{ml})$. The solution was heated at $90 \sim 95^{\circ} \mathrm{C}$ for 1 hour, cooled, neutralized with $5 \mathrm{~N} \mathrm{HCl}(50 \mathrm{ml})$ and filtered through diatomaceous earth. The aqueous phase was concentrated and extracted into ethyl acetate; the organic phase was dried and evaporated to give 2-carboxy-4,5-dimethoxybenzoic acid (2.85 g); ${ }^{1} \mathrm{H} \mathrm{NMR}\left(\mathrm{CDCl}_{3}-\mathrm{DMSO}-d_{6}\right) \delta 3.95$ (s, $6 \mathrm{H}$ ), 7.5 (s, 2H), 11.2 (broad s, $2 \mathrm{H}$ ), mp $196 \sim 198^{\circ} \mathrm{C}\left(\right.$ lit. $^{16)} \mathrm{mp} 198 \sim 199.5^{\circ} \mathrm{C}$ ).

Diacids 13, 30 were prepared in a similar way:

13: yield $25.6 \% ;{ }^{1} \mathrm{H}$ NMR (DMSO- $\left.d_{6}-\mathrm{CF}_{3} \mathrm{COOD}\right) \delta 3.85(\mathrm{~s}, 3 \mathrm{H}), 3.95(\mathrm{~s}, 3 \mathrm{H}), 7.55(\mathrm{~s}, 1 \mathrm{H}$ ); IR $v_{\max } \mathrm{cm}^{-1} 3400 \sim 2400,1720 \sim 1700,1580 ; \mathrm{mp} 194 \sim 196^{\circ} \mathrm{C}$.

Anal Calcd for $\mathrm{C}_{10} \mathrm{H}_{9} \mathrm{O}_{6} \mathrm{Br}$ : $\mathrm{C} 39.36, \mathrm{H} 2.95$.

Found $\quad \mathrm{C} 39.74, \mathrm{H} 3.14$.

30: yield 27\%; ${ }^{1} \mathrm{H}$ NMR (DMSO- $\left.d_{6}-\mathrm{CF}_{3} \mathrm{COOD}\right) \delta 3.74(\mathrm{~s}, 3 \mathrm{H}), 3.9(\mathrm{~s}, 3 \mathrm{H}), 7.1(\mathrm{~d}, 1 \mathrm{H}), 7.7(\mathrm{~d}, 1 \mathrm{H})$; IR $v_{\max } \mathrm{cm}^{-1} 3750 \sim 3200,1700$.

\section{3,4-Dimethoxyphthalimide (14)}

The di-acid $12(1.5 \mathrm{~g}, 6.6 \mathrm{mmol})$ and acetic anhydride $(6 \mathrm{~g})$ were heated at reflux for 1 hour. The mixture was cooled and evaporated to provide dimethoxyphthalic anhydride (1.28 g); ${ }^{1} \mathrm{H}$ NMR (DMSO- $\left.d_{6}\right)$ $\delta 3.99(\mathrm{~s}, 6 \mathrm{H}), 7.6(\mathrm{~s}, 2 \mathrm{H})$.

To the crude anhydride $(2.0 \mathrm{~g}, 9.6 \mathrm{mmol})$ was added $28 \%$ ammonia solution $(2.3 \mathrm{~g})$ and the solution was taken to boiling-point, eliminating water in order to obtain a thick paste.

This was cooled to give a brown solid which was finely ground. This solid was heated by a flame 
(without fusion) to give dimethoxyphthalimide ${ }^{16)}(1.7 \mathrm{~g})$. The reaction was monitored by HPLC. 14 was recristallized using EtOH - petroleum ether. ${ }^{1} \mathrm{H}$ NMR $\left(\mathrm{DMSO}-d_{6}\right) \delta 3.9(\mathrm{~s}, 6 \mathrm{H}), 7.3(\mathrm{~s}, 2 \mathrm{H}), 10.9(\mathrm{~s}, 1 \mathrm{H})$; CI-MS $m / z 225\left(\mathrm{M}+\mathrm{NH}_{4}{ }^{+}\right) ; \mathrm{mp}>320^{\circ} \mathrm{C}$ (lit. $\left.{ }^{16)} \mathrm{mp}>300^{\circ} \mathrm{C}\right)$.

Anal Calcd for $\mathrm{C}_{10} \mathrm{H}_{9} \mathrm{NO}_{4}$ : C 57.97, $\mathrm{H} 4.34, \mathrm{~N} 6.76$.

Found

C $57.73, \mathrm{H} 4.55, \mathrm{~N} 6.78$.

Phthalimides 15, 32 were prepared in a similar way. Intermediate anhydrides were used crude without purification.

15: 1) anhydride: yield $100 \% ;{ }^{1} \mathrm{H}$ NMR (DMSO- $\left.\left.d_{6}\right) \delta 3.85(\mathrm{~s}, 3 \mathrm{H}), 4.1(\mathrm{~s}, 3 \mathrm{H}), 7.75(\mathrm{~s}, 1 \mathrm{H}) ; 2\right)$ 15: yield $100 \%$; ${ }^{1} \mathrm{H}$ NMR (DMSO- $\left.d_{6}\right) \delta 3.85(\mathrm{~s}, 3 \mathrm{H}), 4.0(\mathrm{~s}, 3 \mathrm{H}), 7.47(\mathrm{~s}, 1 \mathrm{H}), 11.25(\mathrm{~m}, 1 \mathrm{H}) ; \mathrm{IR} v_{\max } \mathrm{cm}^{-1}$ $3400 \sim 3100,1770,1740 \sim 1710,1595$; CI-MS $m / z 285,287\left(\mathrm{M}, \mathrm{C}_{10} \mathrm{H}_{8} \mathrm{NO}_{4} \mathrm{Br}\right)$.

32: 1) anhydride 31: yield $100 \%$; ${ }^{1} \mathrm{H}$ NMR (DMSO- $\left.d_{6}\right) \delta 3.98(\mathrm{~s}, 3 \mathrm{H}), 4.05(\mathrm{~s}, 3 \mathrm{H}), 7.6(\mathrm{~d}, 1 \mathrm{H}), 7.8$ $(\mathrm{d}, 1 \mathrm{H}) ;$ IR $\left.v_{\max } \mathrm{cm}^{-1} 1780,1850 ; 2\right)$ 32: yield $50 \% ;{ }^{1} \mathrm{H}$ NMR (DMSO-d $\left.)_{6}\right) \delta 3.92(\mathrm{~s}, 3 \mathrm{H}), 3.97(\mathrm{~s}, 3 \mathrm{H})$, $7.35(\mathrm{~d}, 1 \mathrm{H}), 7.52(\mathrm{~d}, 1 \mathrm{H}), 11.0(\mathrm{~s}, 1 \mathrm{H}) ; \mathrm{IR} v_{\max } \mathrm{cm}^{-1} 3200,1765,1740 \sim 1710,1600 ; \mathrm{mp}$ (EtOH) $\left.225 \sim 228^{\circ} \mathrm{C}^{17}\right)$; CI-MS $m / 2207\left(\mathrm{M}, \mathrm{C}_{10} \mathrm{H}_{9} \mathrm{NO}_{4}\right)$.

\section{3,4-Dihydroxyphthalimide (17)}

To the dimethoxyphthalimide $14(3.1 \mathrm{~g}, .14 .9 \mathrm{mmol})$ were added $\mathrm{BBr}_{3}(12 \mathrm{ml})$ and dichloromethane $(30 \mathrm{ml})$. The suspension was stirred at ambient temperature until HPLC showed that starting material had disappeared. Excess solvent was evaporated and the resultant solid cooled to $0^{\circ} \mathrm{C}$ and treated with ice and then with water $(80 \mathrm{ml})$. The mixture was stirred for 45 minutes at ambient temperature, water $(40 \mathrm{ml})$ removed by evaporation and the residue purified by column chromatography to provide dihydroxyphthalimide $17(2.13 \mathrm{~g}) ;{ }^{1} \mathrm{H}$ NMR (DMSO- $\left.d_{6}\right) \delta 7.1(\mathrm{~s}, 2 \mathrm{H}), 10.25$ (br s, 2H), 11.25 (br s, 1H).

Dihydroxyphthalimides 18, 33 were prepared in a similar way: 18: yield 95\%; ${ }^{1} \mathrm{H}$ NMR (DMSO- $\left.d_{6}\right)$ $\delta 7.1(\mathrm{~s}, 1 \mathrm{H})$; IR $v_{\max } \mathrm{cm}^{-1} 3600 \sim 2900,1760,1720 \sim 1700$.

Anal Calcd for $\mathrm{C}_{8} \mathrm{H}_{4} \mathrm{NO}_{4} \mathrm{Br}$ : C 37.23, $\mathrm{H} 1.56, \mathrm{~N} 5.43$. Found

C $37.59, \mathrm{H} 1.68, \mathrm{~N} 5.20$.

33: yield 68\%; ${ }^{1} \mathrm{H}$ NMR (DMSO-d $\left.d_{6}\right) \delta 7.1(\mathrm{~m}, 2 \mathrm{H}), 10.75(\mathrm{~m}, 1 \mathrm{H})$; IR $v_{\max } \mathrm{cm}^{-1} 3500 \sim 2900,1760$, 1720; EI-MS $m / z 179\left(\mathrm{M}, \mathrm{C}_{8} \mathrm{H}_{5} \mathrm{NO}_{4}\right)$.

\section{3,4-Diphenylmethylenedioxyphthalimide (20)}

A suspension of the dihydroxyphthalimide $17(350 \mathrm{mg}, 19 \mathrm{mmol})$ in diphenyldichloromethane $(4 \mathrm{~g})$ was heated at $160^{\circ} \mathrm{C}$ for 3 hours. The resultant solution was cooled and washed with petroleum ether $(3 \times 10 \mathrm{ml})$. The petrol phase was separated to give a brown oil which was collected and triturated under diethyl ether $(5 \mathrm{ml})$ to give as a chestnet brown solid, diphenylmethylenedioxyphthalimide $20(300 \mathrm{mg}) ;{ }^{1} \mathrm{H}$ NMR (DMSO-d $\left.d_{6}\right) 7.5(\mathrm{~m}, 12 \mathrm{H}), 11.05(\mathrm{~s}, 1 \mathrm{H})$; CI-MS $m / z 344\left(\mathrm{M}+\mathrm{H}^{+}, \mathrm{C}_{21} \mathrm{H}_{14} \mathrm{NO}_{4}\right) ; \mathrm{mp} 170 \sim 173^{\circ} \mathrm{C}$.

Anal Calcd for $\mathrm{C}_{21} \mathrm{H}_{13} \mathrm{NO}_{4}$ : $\mathrm{C} 73.47, \mathrm{H} 3.79, \mathrm{~N} 4.08$.

Found

C $73.03, \mathrm{H} 4.05, \mathrm{~N} 3.96$.

Cooling of the petrol phase afforded a second fraction of the phthalimide $(250 \mathrm{mg})$.

21 and 22 were recristallized from EtOH - petroleum ether.

Phthalimides 35, 36, 21 and 22 were prepared in a similar way:

21: yield $62.5 \%$; ${ }^{1} \mathrm{H}$ NMR (DMSO- $\left.d_{6}\right) \delta 7.5(\mathrm{~s}, 1 \mathrm{H}), 7.55(\mathrm{~s}, 10 \mathrm{H}) ;$ IR $v_{\max } \mathrm{cm}^{-1} 3400 \sim 3100,1780$, 1715 ; $\mathrm{mp} 194 \sim 196^{\circ} \mathrm{C}$; CI-MS $m / z$ 422, $424\left(\mathrm{M}+\mathrm{H}^{+}, \mathrm{C}_{21} \mathrm{H}_{13} \mathrm{NO}_{4} \mathrm{Br}\right)$.

Anal Calcd for $\mathrm{C}_{21} \mathrm{H}_{12} \mathrm{NO}_{4} \mathrm{Br}$ : C 59.71, $\mathrm{H} 2.84, \mathrm{~N} 3.31$.

Found $\quad \mathrm{C} 59.55, \mathrm{H} 2.96, \mathrm{~N} 3.35$

22: yield $58 \% ;{ }^{1} \mathrm{H}$ NMR (DMSO- $\left.d_{6}\right) \delta 7.5\left(\mathrm{~s}, 10 \mathrm{H}\right.$ ); IR $v_{\max } \mathrm{cm}^{-1} 3200,1770,1720$; white plates mp $230 \sim 232^{\circ} \mathrm{C}$; CI-MS $m / z 412,414\left(\mathrm{M}+\mathrm{H}^{+}, \mathrm{C}_{21} \mathrm{H}_{12} \mathrm{NO}_{4} \mathrm{Cl}_{2}\right)$.

Anal Calcd for $\mathrm{C}_{21} \mathrm{H}_{11} \mathrm{NO}_{4} \mathrm{Cl}_{2}$ : C 61.16, H 2.70, N 3.42 .

Found

C $61.23, \mathrm{H} 2.89, \mathrm{~N} 3.39$.

35: yield $49 \% ;{ }^{1} \mathrm{H}$ NMR (DMSO- $\left.d_{6}\right) \delta 7.4(\mathrm{~s}, 2 \mathrm{H}), 7.55(\mathrm{~s}, 10 \mathrm{H}), 11.2(\mathrm{~s}, 1 \mathrm{H}) ;$ IR $v_{\max } \mathrm{cm}^{-1} 1770$, 
1720, 1700; CI-MS $m / z 343\left(\mathrm{M}, \mathrm{C}_{21} \mathrm{H}_{13} \mathrm{NO}_{4}\right)$.

36: yield $80 \%$; ${ }^{1} \mathrm{H}$ NMR (DMSO- $\left.d_{6}\right) \delta 7.55\left(\mathrm{~s}, 11 \mathrm{H}\right.$ ), IR $v_{\max } \mathrm{cm}^{-1} 1770,1720$.

Anal Calcd for $\mathrm{C}_{21} \mathrm{H}_{12} \mathrm{NO}_{4} \mathrm{Br}$ : C 59.71, H 2.84, N 3.31.

Found

C 59.84, H 3.04, N 3.30 .

$N$-Carboethoxy-3,4-diphenylmethylenedioxyphthalimide (23)

To a suspension of sodium hydride $(4 \mathrm{mg}, 50 \%$ ) (washed with tetrahydrofuran) was added, dropwise, a solution of phthalimide $20(500 \mathrm{mg}, 1.45 \mathrm{mmol})$, in DMF $(1.5 \mathrm{ml})$. The mixture was stirred for 1 hour at ambient temperature, cooled to $0^{\circ} \mathrm{C}$ and ethyl chloroformate $(180 \mu 1)$ was added dropwise. The resultant solution was stirred at $0^{\circ} \mathrm{C}$ for 5 minutes, stirred at ambient temperature for 3 hours, cooled to $0^{\circ} \mathrm{C}$ and water $(5 \mathrm{ml})$ added with stirring. The solution was extracted with diethyl ether $(150 \mathrm{ml})$. The ether phase was washed with water $(3 \times 20 \mathrm{ml})$, saturated $\mathrm{NaCl}(20 \mathrm{ml})$, dried, filtered and evaporated to give $N$-carboethoxy diphenylmethylenedioxyphthalimide $(600 \mathrm{mg}) ;{ }^{1} \mathrm{H}$ NMR $\left(\mathrm{CDCl}_{3}\right) \delta 1.40(\mathrm{t}, 3 \mathrm{H}), 4.45$ (q, $2 \mathrm{H}), 7.25 \sim 7.75(\mathrm{~m}, 12 \mathrm{H})$.

$N$-Carboethoxyphthalimides 24, 25, 37 and 38 were prepared in a similar way. Compounds 23,24 , 38 decomposes partially when purified over silica or HP20SS resines and have thus been used crude in the next step.

24: yield 95\%; ${ }^{1} \mathrm{H}$ NMR (DMSO- $\left.d_{6}-\mathrm{CF}_{3} \mathrm{COOD}\right) \delta 1.3(\mathrm{t}, 3 \mathrm{H}), 4.3(\mathrm{q}, 2 \mathrm{H}), 7.25 \sim 7.75(\mathrm{~m}, 11 \mathrm{H})$ ).

25: yield $100 \%$; ${ }^{1} \mathrm{H}$ NMR (DMSO- $\left.d_{6}\right) \delta 1.3(\mathrm{t}, 3 \mathrm{H}), 4.35(\mathrm{q}, 2 \mathrm{H}), 7.55(\mathrm{~s}, 10 \mathrm{H})$; IR $v_{\max } \mathrm{cm}^{-1} 1680$. Recrystallized 3 times from EtOH. mp $158 \sim 160^{\circ} \mathrm{C}$; CI-MS $m / z 484,486\left(\mathrm{M}+\mathrm{H}^{+}, \mathrm{C}_{24} \mathrm{H}_{16} \mathrm{NO}_{6} \mathrm{Cl}_{2}\right)$.

Anal Calcd for $\mathrm{C}_{24} \mathrm{H}_{15} \mathrm{NO}_{6} \mathrm{Cl}_{2}$ : C 59.50, H 3.10, $\mathrm{N} 2.89$. Found

C 59.48, H 3.30, N 2.94 .

37: yield 74.2\%; ${ }^{1} \mathrm{H}$ NMR $\left(\mathrm{CDCl}_{3}\right) \delta 1.45(\mathrm{t}, 3 \mathrm{H}), 4.45$ (q, 2H), $7.2 \sim 7.7(\mathrm{~m}, 12 \mathrm{H})$; IR $v_{\max } \mathrm{cm}^{-1}$ $1800,1780,1720$; CI-MS $m / z 415\left(\mathrm{M}, \mathrm{C}_{24} \mathrm{H}_{17} \mathrm{NO}_{6}\right)$.

38: yield $81.5 \% ;{ }^{1} \mathrm{H}$ NMR (DMSO- $\left.d_{6}\right) \delta 1.35(\mathrm{t}, 3 \mathrm{H}), 4.4(\mathrm{q}, 2 \mathrm{H}), 7.55(\mathrm{~s}, 11 \mathrm{H}) ; \mathrm{IR} v_{\max } \mathrm{cm}^{-1} 1800$, 1760,1720 .

7-[2-(2-Aminothiazol-4-yl)-2-((Z)-1-carboxy-1-methylethoxyimino)acetamido]-3-(5,6-diphenylmethylenedioxy-1,3-dioxo-isoindol-2-ylmethyl)ceph-3-em-4-carboxylic Acid (26)

To a solution of 7-[2-(2-aminothiazol-4-yl)-2-((Z)-1-carboxy-1-methylethoxyimino)acetamido]-3aminomethylceph-3-em-4-carboxylic acid $41(143 \mathrm{mg})$ in DMSO $(2 \mathrm{ml})$ was added triethylamine $(62.4 \mathrm{mg})$ followed by the phthalimide $23(85.6 \mathrm{mg}, 0.21 \mathrm{mmol})$ in DMSO $(1 \mathrm{ml})$.

The solution was stirred at ambient temperature for 90 minutes, concentrated $\mathrm{HCl}$ ( 10 drops) added and after storage at $3^{\circ} \mathrm{C}$ for 12 hours the solution was evaporated and purified by column chromatography using HP20SS resin to give $26(70 \mathrm{mg}) ;{ }^{1} \mathrm{H}$ NMR (DMSO- $\left.d_{6}-\mathrm{CF}_{3} \mathrm{COOD}\right) \delta 1.5(2 \mathrm{~s}, 6 \mathrm{H}), 3.3(\mathrm{~d}, 1 \mathrm{H}), 3.6$ $(\mathrm{d}, 1 \mathrm{H}), 4.4(\mathrm{~d}, 1 \mathrm{H}), 4.90(\mathrm{~d}, 1 \mathrm{H}), 5.1(\mathrm{~d}, 1 \mathrm{H}), 5.8(\mathrm{~d}, 1 \mathrm{H}), 7.05(\mathrm{~s}, 1 \mathrm{H}), 7.25 \sim 7.75(\mathrm{~m}, 12 \mathrm{H})$.

$27,28,39$ and 40 were prepared in a similar way:

27: yield $61 \%$; ${ }^{1} \mathrm{H}$ NMR (DMSO- $\left.d_{6}-\mathrm{CF}_{3} \mathrm{COOD}\right) \delta 1.5(2 \mathrm{~s}, 6 \mathrm{H}), 3.25(\mathrm{dAB}, 1 \mathrm{H}), 3.7(\mathrm{dAB}, 1 \mathrm{H})$, $4.35(\mathrm{dAB}, 1 \mathrm{H}), 4.9(\mathrm{dAB}, 1 \mathrm{H}), 5.1(\mathrm{~d}, 1 \mathrm{H}), 5.85(\mathrm{~d}, 1 \mathrm{H}), 7.05(\mathrm{~s}, 1 \mathrm{H}), 7.25 \sim 7.75(\mathrm{~m}, 1 \mathrm{H}) ; \mathrm{IR} v_{\max } \mathrm{cm}^{-1}$ $3700 \sim 2700,1770,1710$; FAB-MS $m / z 889,891\left(\mathrm{M}+\mathrm{H}^{+}, \mathrm{C}_{38} \mathrm{H}_{30} \mathrm{~N}_{6} \mathrm{O}_{11} \mathrm{~S}_{2} \mathrm{Br}\right)$.

28: yield 63.1\%; ${ }^{1} \mathrm{H}$ NMR (DMSO- $\left.d_{6}-\mathrm{CF}_{3} \mathrm{COOD}\right) \delta 1.5(2 \mathrm{~s}, 6 \mathrm{H}), 3.3(\mathrm{dAB}, 1 \mathrm{H}), 3.65(\mathrm{dAB}, 1 \mathrm{H})$, $4.4(\mathrm{dAB}, 1 \mathrm{H}), 4.9(\mathrm{dAB}, 1 \mathrm{H}), 5.1(\mathrm{~d}, 1 \mathrm{H}), 5.85(\mathrm{~d}, 1 \mathrm{H}), 7.05(\mathrm{~s}, 1 \mathrm{H}), 7.55(\mathrm{~s}, 10 \mathrm{H}) ;$ FAB-MS $m / z$ 879, 881 $\left(\mathrm{M}+\mathrm{H}^{+}, \mathrm{C}_{38} \mathrm{H}_{29} \mathrm{~N}_{6} \mathrm{O}_{11} \mathrm{~S}_{2} \mathrm{Cl}_{2}\right)$.

39: yield $59.5 \%$ (not purified; used crude in the next step).

40: yield 69\%; ${ }^{1} \mathrm{H}$ NMR (DMSO- $\left.d_{6}\right) \delta 1.54(\mathrm{~s}, 3 \mathrm{H}), 1.56(\mathrm{~s}, 3 \mathrm{H}), 3.3(\mathrm{dAB}, 1 \mathrm{H}), 3.65(\mathrm{dAB}, 1 \mathrm{H}), 4.4$ $(\mathrm{dAB}, 1 \mathrm{H}), 4.9(\mathrm{dAB}, 1 \mathrm{H}), 5.1(\mathrm{~d}, 1 \mathrm{H}), 5.85(\mathrm{~d}, 1 \mathrm{H}), 7.05(\mathrm{~s}, 1 \mathrm{H}), 7.5(\mathrm{~s}, 10 \mathrm{H}), 7.65(\mathrm{~s}, 1 \mathrm{H}) ; \mathrm{IR} v_{\max } \mathrm{cm}^{-1}$ 1770,$1710 ;$ FAB-MS $m / z 889,891\left(\mathrm{M}+\mathrm{H}^{+}, \mathrm{C}_{38} \mathrm{H}_{30} \mathrm{~N}_{6} \mathrm{O}_{11} \mathrm{~S}_{2} \mathrm{Br}\right)$.

7-[2-(2-Aminothiazol-4-yl)-2-((Z)-1-carboxy-1-methylethoxyimino)acetamido]-3-(5,6-dihydroxy-1,3dioxo-isoindol-2-ylmethyl)ceph-3-em-4-carboxylic Acid (3)

To 7-[2-(2-aminothiazol-4-yl)-2-((Z)-1-carboxy-1-methylethoxyimino)acetamido]-3-(5,6-dipheny]methylenedioxy-1,3-dioxo-isoindol-2-ylmethyl)ceph-3-em-4-carboxylic acid (26) (70 mg) was added tri- 
fluoroacetic acid $(4 \mathrm{ml})$ followed by water ( 2 drops).

The solution was stirred for 4 hours at ambient temperature. The solvent was removed by evaporation and the solid residue was diluted with dimethylformamide $(3 \mathrm{ml})$ and subjected to column chromatography using HP20SS resin to afford the title compound $\left(30 \mathrm{mg}\right.$ ); ${ }^{1} \mathrm{H}$ NMR (DMSO- $d_{6}-\mathrm{CD}_{3} \mathrm{COOD}-\mathrm{CF}_{3} \mathrm{COOD}$ ) $\delta 1.5(2 \mathrm{~s}, 6 \mathrm{H}), 3.25(\mathrm{~d}, 1 \mathrm{H}), 3.55(\mathrm{~d}, 1 \mathrm{H}), 4.35(\mathrm{~d}, 1 \mathrm{H}), 4.8(\mathrm{~d}, 1 \mathrm{H}), 5.1(\mathrm{~d}, 1 \mathrm{H}), 5.8(\mathrm{~d}, 1 \mathrm{H}), 7.05(\mathrm{~s}, 1 \mathrm{H})$, 7.1 (s, 2H); FAB-MS $m / z 647(\mathrm{M}+\mathrm{H})$; IR $v_{\max } \mathrm{cm}^{-1} 1755,1700$.

4, 5, 6 and 7 were prepared in a similar way:

4: yield $66 \% ;{ }^{1} \mathrm{H}$ NMR (DMSO- $\left.d_{6}-\mathrm{CF}_{3} \mathrm{COOD}-\mathrm{CD}_{3} \mathrm{COOD}\right) \delta 1.5(2 \mathrm{~s}, 6 \mathrm{H}), 3.25(\mathrm{dAB}, 1 \mathrm{H}), 3.55$ $(\mathrm{dAB}, 1 \mathrm{H}), 4.35(\mathrm{dAB}, 1 \mathrm{H}), 4.9(\mathrm{dAB}, 1 \mathrm{H}), 5.1(\mathrm{dAB}, 1 \mathrm{H}), 5.8(\mathrm{dAB}, 1 \mathrm{H}), 7.05(\mathrm{~s}, 1 \mathrm{H}), 7.15(\mathrm{~s}, 1 \mathrm{H})$; IR $v_{\max } \mathrm{cm}^{-1} 3700 \sim 3400,1770,1700$; FAB-MS $m / z 723(\mathrm{M}-\mathrm{H})$.

5: yield $38 \% ;{ }^{1} \mathrm{H}$ NMR (DMSO- $\left.d_{6}-\mathrm{CF}_{3} \mathrm{COOD}-\mathrm{CD}_{3} \mathrm{COOD}\right) \delta 1.5(2 \mathrm{~s}, 6 \mathrm{H}), 3.3(\mathrm{dAB}, 1 \mathrm{H}), 3.6(\mathrm{dAB}$, $1 \mathrm{H}), 4.35(\mathrm{dAB}, 1 \mathrm{H}), 4.9(\mathrm{dAB}, 1 \mathrm{H}), 5.1(\mathrm{~d}, 1 \mathrm{H}), 5.8(\mathrm{~d}, 1 \mathrm{H}), 7.05(\mathrm{~s}, 1 \mathrm{H}) ; \mathrm{R} v_{\max } \mathrm{cm}^{-1} 1760,1700$; FAB-MS $m / z 715(\mathrm{M}+\mathrm{H})$.

6: yield $66 \% ;{ }^{1} \mathrm{H}$ NMR (DMSO- $\left.d_{6}-\mathrm{CF}_{3} \mathrm{COOD}-\mathrm{CD}_{3} \mathrm{COOD}\right) \delta 1.52(\mathrm{~s}, 6 \mathrm{H}), 3.35(\mathrm{~d}, 1 \mathrm{H}), 3.6(\mathrm{~d}$, $1 \mathrm{H}), 4.35(\mathrm{dAB}, 1 \mathrm{H}), 4.9(\mathrm{dAB}, 1 \mathrm{H}), 5.15(\mathrm{~d}, 1 \mathrm{H}), 5.8(\mathrm{~d}, 1 \mathrm{H}), 7 \sim 7.25(\mathrm{~m}, 3 \mathrm{H}) ; \mathrm{IR} v_{\max } \mathrm{cm}^{-1} 1760,1700$; FAB-MS $m / z 645(\mathrm{M}-\mathrm{H})$.

7: yield $61 \%$; ${ }^{1} \mathrm{H}$ NMR (DMSO- $\left.d_{6}-\mathrm{CF}_{3} \mathrm{COOD}-\mathrm{CD}_{3} \mathrm{COOD}\right) \delta 1.53(2 \mathrm{~s}, 6 \mathrm{H}), 3.3(\mathrm{dAB}, 1 \mathrm{H}), 3.6$ $(\mathrm{dAB}, 1 \mathrm{H}), 4.4(\mathrm{dAB}, 1 \mathrm{H}), 4.95(\mathrm{dAB}, 1 \mathrm{H}), 5.15(\mathrm{~d}, 1 \mathrm{H}), 5.8(\mathrm{~d}, 1 \mathrm{H}), 7.05(\mathrm{~s}, 1 \mathrm{H}), 7.45(\mathrm{~s}, 1 \mathrm{H}) ; \mathrm{IR} v_{\max } \mathrm{cm}^{-1}$ $1760,1700,1630 ;$ FAB-MS $m / z 723(\mathrm{M}-\mathrm{H})$.

7-[2-(2-Aminothiazol-4-yl)-2-((Z)-1-carboxy-1-methylethoxyimino)acetamido]-3-(1,3-dioxo-isoindol2-ylmethyl)ceph-3-em-4-carboxylic Acid (8)

To 7-[2-(2-aminothiazol-4-yl)-2-((Z)-1-carboxy-1-methylethoxyimino)acetamido]-3-aminomethylceph-3-em-4-carboxylic acid ( $200 \mathrm{mg})$ in DMSO $(2 \mathrm{ml})$ was added triethylamine $(55 \mathrm{mg}, 0.56 \mathrm{mmol})$ followed by $N$-carboethoxyphthalimide $(41 \mathrm{mg}, 0.186 \mathrm{mmol})$. The solution was stirred at ambient temperature for 6 hours, concentrated $\mathrm{HCl}\left(6\right.$ drops) added and after storage at $3^{\circ} \mathrm{C}$ for 12 hours, the solution was evaporated and purified by column chromatography using HP20SS resin to afford the title compound $(30 \mathrm{mg}) ;{ }^{1} \mathrm{H}$ NMR (DMSO- $\left.d_{6}-\mathrm{CF}_{3} \mathrm{COOD}-\mathrm{CD}_{3} \mathrm{COOD}\right) \delta 1.5(\mathrm{~s}, 6 \mathrm{H}), 3.35(\mathrm{~d}, 1 \mathrm{H}), 3.65(\mathrm{~d}, 1 \mathrm{H}), 4.45(\mathrm{~d}$, $1 \mathrm{H}), 5.0(\mathrm{~d}, 1 \mathrm{H}), 5.15(\mathrm{~d}, 1 \mathrm{H}), 5.85(\mathrm{~d}, .1 \mathrm{H}), 7.05(\mathrm{~s}, 2 \mathrm{H}), 7.85(\mathrm{~s}, 4 \mathrm{H})$; FAB-MS $m / z 613(\mathrm{M}-\mathrm{H})$.

\section{3-Bromo-4,5-dimethoxytoluene (16)}

1) Bromine $(16 \mathrm{~g}, 0.1 \mathrm{~mol})$ was added dropwise to a solution of vanillin $(15.2 \mathrm{~g}, 0.1 \mathrm{~mol})$ in acetic acid $(66 \mathrm{ml})$ and the mixture stirred 12 hours at ambient temperature. The resulting solid was filtered and washed with ethanol to give bromovanillin ( $16.5 \mathrm{~g}$ ); yield: $72 \%$; ${ }^{1} \mathrm{H}$ NMR (DMSO- $\left.d_{6}\right) \delta 3.9(\mathrm{~s}, 3 \mathrm{H}), 7.3$ (s, 1H), $7.6(\mathrm{~s}, 1 \mathrm{H}), 9.7(\mathrm{~s}, 1 \mathrm{H}) ; \mathrm{IR} v_{\max } \mathrm{cm}^{-1} 3500 \sim 3000,1680$.

2) To a solution of bromovanillin $(8 \mathrm{~g}, 34.6 \mathrm{mmol})$ in DMF $(65 \mathrm{ml})$ was added potassium carbonate $(9.7 \mathrm{~g}, 69.2 \mathrm{mmol})$ followed by dimethylsulfate $(5 \mathrm{ml}, 51.9 \mathrm{mmol})$. Stirring was continued 3 days at ambient temperature after which water $(400 \mathrm{ml})$ was added. The precipitate was filtered and recrystallized (petroleum ether) to afford 3-bromo-4,5-dimethoxybenzaldehyde (6g); yield: 70\%; ${ }^{1} \mathrm{H}$ NMR (DMSO- $d_{6}-\mathrm{CF}_{3} \mathrm{COOD}$ ) $\delta 3.87(\mathrm{~s}, 3 \mathrm{H}), 3.94(\mathrm{~s}, 3 \mathrm{H}), 7.5(\mathrm{~s}, 1 \mathrm{H}), 7.76(\mathrm{~s}, 1 \mathrm{H}), 9.9(\mathrm{~s}, 1 \mathrm{H})$.

Anal Calcd for $\mathrm{C}_{9} \mathrm{H}_{9} \mathrm{O}_{3} \mathrm{Br}$ : C 44.09, $\mathrm{H} 3.70$.

Found

C $44.36, \mathrm{H} 3.81$.

3) A solution of 3-bromo-4,5-dimethoxybenzaldehyde $(3 \mathrm{~g}, 12.2 \mathrm{mmol})$ and hydrazine hydrate $(15 \mathrm{~g})$ in diethylene glycol $(25 \mathrm{ml})$ was heated at $90 \sim 100^{\circ} \mathrm{C}$ for 45 minutes. After cooling to ambient temperature $\mathrm{KOH}(1 \mathrm{~g})$ was added and the solution was heated at $140 \sim 160^{\circ} \mathrm{C}$ for 3 hours. After cooling the solution was poured into water $(50 \mathrm{ml})$ and extracted with ether; the organic layer was washed with brine and dried $\left(\mathrm{MgSO}_{4}\right)$ to give the title compound $16^{\dagger}$ as an oil $\left(1.69 \mathrm{~g}\right.$ ); yield: $60 \% ;{ }^{1} \mathrm{H}$ NMR (DMSO- $\left.d_{6}\right) \delta 2.27$ (s, $3 \mathrm{H}), 3.7(\mathrm{~s}, 3 \mathrm{H}), 3.8(\mathrm{~s}, 3 \mathrm{H}), 6.9(\mathrm{~s}, 1 \mathrm{H}), 6.97(\mathrm{~s}, 1 \mathrm{H})$; IR $v_{\max } \mathrm{cm}^{-1} 1600$.

$\dagger$ NMR given in DMSO- $d_{6}$ for consistency -A sample ran in $\mathrm{CCl}_{4}$ gave identical results to literature 18 . 
2,3-Dihydroxy-4-bromophthalimide (34)

A solution of phthalimide $33(0.26 \mathrm{~g}, 1.4 \mathrm{mmol})$ and bromine $(0.23 \mathrm{~g}, 1.4 \mathrm{mmol})$ in acetic acid $(13 \mathrm{ml})$ was stirred 3 hours at $50^{\circ} \mathrm{C}$. After 3 hours a further portion of bromine $(0.23 \mathrm{~g})$ in acetic acid $(3 \mathrm{ml})$ was added and heating continued for 1 hour at $50^{\circ} \mathrm{C}$ and 3 hours at $80^{\circ} \mathrm{C}$. After cooling and filtration the precipitate was washed with acetic acid and dried to give $34(350 \mathrm{mg})$; yield: $100 \% ;{ }^{1} \mathrm{H}$ NMR (DMSO- $d_{6}$ ) $\delta 7.4(\mathrm{~s}, 1 \mathrm{H}) ; \mathrm{IR} v_{\max } \mathrm{cm}^{-1} 1750,1700$.

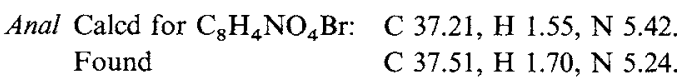

2,5-Dichloro-3,4-dihydroxyphthalimide (19)

To a suspension of $17(0.4 \mathrm{~g}, 2.2 \mathrm{mmol})$ in acetic acid $(12 \mathrm{ml})$ was added $N$-chlorosuccinimide $(0.61 \mathrm{~g}$, $4.6 \mathrm{mmol})$. After stirring 6 minutes at ambiant temperature paratoluenesulfonic acid $(10 \mathrm{mg}, 0.05 \mathrm{mmol})$ was added and the mixture heated at $60^{\circ} \mathrm{C}$ for 6 hours. After cooling, the precipitate was filtered off and dried overnight under vaccum $\left(0.52 \mathrm{~g}\right.$ ); yield: $94 \% ;{ }^{1} \mathrm{H}$ NMR (DMSO- $\left.d_{6}, \mathrm{CF}_{3} \mathrm{COOD}\right) \delta:$ No signals; CI-MS $m / z$ $247,249,251\left(\mathrm{M}, \mathrm{C}_{8} \mathrm{H}_{3} \mathrm{NO}_{4} \mathrm{Cl}_{2}\right)$.
Anal Caled for $\mathrm{C}_{8} \mathrm{H}_{3} \mathrm{NO}_{4} \mathrm{Cl}_{2}$ : C 38.71, $\mathrm{H} 1.2 \mathrm{i}, \mathrm{N} 5.65$. Found C $38.95, \mathrm{H} 1.37$, N 5.50 .

\section{Conclusion}

Introduction of an ortho dihydroxyphthalimido residue at C-3' of the cephalosporin nucleus has led to compounds possessing exceptional in vitro antibacterial activity against Gram-negative becteria, in particular $P$. aeruginosa. Furthermore these compounds have shown exceptional $\beta$-lactamase stability, this being related to the planarity of the substituent and to the $\mathrm{p} K \mathrm{a}$ of the catechol moiety. In the marmosets, several of these compounds also possess outstanding pharmacokinetics (equivalent or superior to ceftriaxone) which seemed highly dependent on the $\mathrm{pKa}$ of the hydroxy groups.

\section{Acknowledgment}

The authors thanks Dr. J. M. Girodeau for helpful discussions, Drs. T. D. Hennessey, N. A. C. CurTis and Mr. R. G. WILSON and their colleagues at ICI Pharmaceuticals (Bacteriology Unit) for performing the in vitro biological testing and the determination of pharmacokinetics, serum protein binding and urinary recovery in animals models.

\section{References}

1) Arnould, L. C.; A. Bertrandie, T. G. C. Bird, D. Boucherot, F. Jung, J. J. lohmann, A. Olivier, J. P. BAILEY, W. Bell \& G. M. DAvies: Synthesis and structure-activity relationships of cephalosporins with C-3' catechol containing-residues. J. Med. Chem. 35: 2631 2642, 1992

2) O'Callaghan, C. H.: Description and classification of new cephalosporins and their relationship with the established compounds. J. Antimicrob. Chemother. 5: 635 671, 1979

3) KatZU, K.; K. Кitoh, M. INOUE \& S. Mirsuhashr: In vitro antibacterial activity of E-0702, a new semi-synthetic cephalosporin. Antimicrob. Agents Chemother. 22: 181 185, 1982

4) Branch, C. L.; M. J. Basker, S. C. Finch, A. W. Guest, F. P. Harrington, A. C. Kaura, S. J. Knott, P. H. Milner \& M. J. Pearson: Studies on semi-synthetic $7 \alpha$-formamidocephalosporins. III. Synthesis and antibacterial activity of some 7 $\beta$-[D-2-(aryl)-2-[4-ethyl-2,3-dioxopiperazin-1-yl)carbonylamino] acetamido]-7 $\alpha$-formamidoceph3-em-4-carboxylate derivatives. J. Antibiotics 40: 646 651, 1987

5) Mochida, K.; Y. Ono, M. Yamasaki, C. Shiraki, T. Hirata, K. Sato \& R. OKachi: Aminothiazolylglycyl derivatives of carbacephem antibiotics. II. Synthesis and antibacterial activity of novel aminothiazolyl cephem compounds with hydroxypyridone moiety. J. Antibiotics 40: 182 189, 1987

6) Mochizuki, H.; H. Yamada, Y. Oikawa, K. Murakami, J. Ishiguro, H. Kosuzume, N. Aizawa \& E. Mochida: Bactericidal activity of M14659 enhanced in low-iron environments. Antimicrob. Agents Chemother. 32: $1648 \sim 1654,1988$

7) Watanabe, N.; T. NAGASU, K. Katsu \& K. Кitoh: E-0702, a new cephalosporin, is incorporated into Escherichia coli cells via the ton B-dependent iron transport system. Antimicrob. Agents Chemother. 31: 497 504, 1987

8) Curtis, N. A. C.; R. L. Eisenstadt, S. J. East, R. J. Cornford, L. A. Walker \& A. J. White: Iron regulated outer membrane proteins of Escherichia coli $\mathrm{K} 12$ and mechanism of action of catechol substituted cephalosporins. 
Antimicrob. Agents Chemother. 32: 1879 1886, 1988

9) Bird, T. G. C.; J. C. Arnould, A. Bertrandie \& F. H. Jung: Pharmacokinetics of catechol cephalosporins. The effect of incorporating substituents into the catechol moiety on pharmacokinetics in a marmoset model. J. Med. Chem. 35: 2643 2651, 1992

10) Hennequin, L. F. A. \& D. M. Hollinshead (Imperial Chemical Industries PLC; ICI-pharma S. A.): Preparation of cephalosporins as bactericides. Eur. Pat. 412763 A2, 1991 (CA 115, 28977r, 1991)

11) Neefkens, G. H. L.; G. I. Tesser \& R. J. F. Nivard: A simple preparation of phthaloyl amino acids via a mild phthaloylation. Red. Trav; Chim. PAYS BAS 79: 688 698, 1960

12) Ohi, N.; B. Aoki, T. Kuroki, M. Matsumoto, K. Kojima \& T. Nehashi: Semisynthetic $\beta$-lactam antibiotics. III. Effect on antibacterial activity and COMT-susceptibility of chlorine-introduction into the catechol nucleus of 6-[(R)-2-[3-(3,4-dihydroxybenzoyl)-3-(3-hydroxypropyl)-1-ureido]-2-phenylacetamido]penicillanic acid. J. Antibiotics 40: $22 \sim 28,1987$

13) Flynn, E. H. (Ed.): Cephalosporins and Penicillins, Chemistry and Biology. Academic Press, 162, 1972

14) Charlton, J. L.; K. KoH \& G. L. Plourde: An asymetric synthesis of 2-amino-6,7-dihydroxy-1,2,3,4tetrahydronaphthatalene (ADTN). Can. J. Chem. 68: 2028 2031, 1990

15) ByCK, J. S. \& R. C. Dawson: The synthesis of compounds structurally related to poison Ivy Urushiol. 4-methyl-, 5-methyl-, 6-methyl-, and 4,5,6-trimethyl-3-pentadecylcatechol. J. Org. Chem. 33: 2451 2458, 1968

16) ANDERSON, D. R. \& T. H. Koch: 2,3-Bis(trimethylsyliloxy)-1,3-butadiene as a useful reactive diene in the Diels-Alder reaction. J. Org. Chem. 43: 2726 2728, 1978

17) RöNsCH, H.: On papaver bracteatum-XIV. Ready access to benzylidene phthalimidine compounds from rhoeadine alkaloid-derived nitriles. Tetrahedron 37: 371 375, 1981

18) McKillop, A.; A. G. Turrell, D. W. Young \& E. C. TaYlor: Thallium in organic synthesis. 58. Regiospecific intermolecular oxidative dehydrodimerization of aromatic compounds to biaryls using thallium (III) triffuoroacetate. J. Am. Chem. Soc. 102: 6504 6512, 1980 